\title{
Towards Non-Invasive Bedside Monitoring of Cerebral Blood Flow and Oxygen Metabolism in Brain-Injured Patients with Near-Infrared Spectroscopy
}

\author{
Mamadou Diop, Jonathan T. Elliott, Ting-Yim Lee and Keith St. Lawrence \\ Imaging Division, Lawson Health Research Institute \\ London, Ontario \\ Canada
}

\section{Introduction}

Monitoring the injured brain to detect and treat harmful events that can cause secondary injury during the acute recovery period is a central part of neurointensive care. The most basic monitoring tool is the neurological examination, such as the Glasgow Coma Score; however, a large component of this scale involves verbal communication and braininjured patents are often comatose, mechanically ventilated or sedated. As well, symptoms of neurological deterioration detected by examination often occur at late stages of brain injury. Since the brain is extremely vulnerable to ischemia, a more direct indicator of potential brain injury is detecting impaired cerebral blood flow (CBF). Multiple factors following brain injury can cause ischemia, including systemic hypotension, cerebral hemorrhage, and edema - all of which independently worsen survival (Helmy et al., 2007). This focus has lead to the recognition that continuous monitoring of CBF in patients with, or at risk of, brain injury could improve outcome by providing the ability to detect and prevent cerebral ischemia.

Imaging techniques, such as magnetic resonance imaging (MRI) and computed tomography (CT), are critical to the management of brain-injured patients as they provide detailed structural and functional information of the brain when patients are admitted to an emergency department (Gallagher et al., 2007). CT is the modality of choice because it is widely available and examination times are relatively short. Furthermore, techniques for measuring CBF have been developed on these imaging modalities (Wintermark et al., 2005) and subsequently used to identify CBF abnormalities following brain injury (DeWitt \& Prough, 2003; Gowda et al., 2006; Soustiel et al., 2008). Despite these promising advances, conventional imaging modalities suffer from serious disadvantages regarding cerebral monitoring. First, they require transferring patients to imaging facilities which represents a significant risk factor when dealing with critically ill patients. Second, they only provide a single time-point measurement and, therefore, suffer from the possibility of missing flow abnormalities that occur at different times during intensive care. Clearly, effective cerebral monitoring requires bedside techniques. 
Since $\mathrm{CBF}$ is driven in part by the cerebral perfusion pressure (CPP) which depends on intracranial pressure (ICP), using these pressures as surrogate markers of $\mathrm{CBF}$ is becoming an integral part of critical care practice. Intracranial pressure is typically measured using either a ventricular catheter or an intraparenchymal probe, and CPP is determined by the difference between mean arterial pressure (MAP) and ICP. Although there have been no large randomized trials comparing target thresholds, it is generally recommended that the ICP threshold above which treatment should be initiated is between $20-25 \mathrm{~mm} \mathrm{Hg}$ (Bratton et al., 2007b). Similarly, CPP should be maintained above $60 \mathrm{~mm} \mathrm{Hg}$ to ensure adequate CBF (Bratton et al., 2007a). However, the thresholds for ICP and CPP remain a source of contention. Increasing CPP (70-90 $\mathrm{mm} \mathrm{Hg}$ ) was found to reduce ischemia (Coles et al., 2004), but comes at the cost of increased incidence of extracranial complications and possibly contributes to vasogenic edema (Robertson et al., 1999). The Lund protocol advises a lower limit of $50 \mathrm{~mm} \mathrm{Hg}$ to prevent complications while avoiding extremely low CBF (Asgeirsson et al., 1994). It has even been suggested that CPP/ICP therapy only increases therapy intensity without improving outcome (Cremer, 2008). Strictly adhering to targets can therefore give clinicians a false sense of security. A method of measuring CBF at the bedside would remove this ambiguity since the occurrence of ischemia due to inadequate CPP or hyperemia due to excessive CPP therapy would be readily apparent.

The most widely used beside technique for monitoring CBF is transcranial Doppler (TCD). This non-invasive technique derives blood flow velocity from the Doppler shift caused by moving red blood cells in a cerebral artery. Provided the angle of insonation and the diameter of the interrogated vessel remain constant, changes in TCD measurements reflect CBF changes (Valdueza et al., 1997). However, the accuracy of TCD is operator dependent due to problems of probe fixation, the TCD signal is not found in $10-30 \%$ of patients, and the technique cannot monitor blood flow in the microvasculature, which can be quite different from flow in the major arteries (Wright, 2007). Invasive techniques for monitoring CBF that require inserting probes directly into brain tissue include laser Doppler (LDF) and thermal diffusion flowmetry (TDF) (Bolognese et al., 1993; Sioutos et al., 1995). These techniques have been used to detect ischemia in brain-injured patients and TDF was shown to be more sensitive than TCD to assessing vasospasm, demonstrating the value of assessing CBF directly (Kirkpatrick et al., 1994; Vajkoczy et al., 2001). Besides being invasive, the major limitation with LDF and TDF is that they can only monitor the vascular territory where the probes are placed. Wider applicability of $\mathrm{CBF}$ monitoring requires non-invasive techniques that can assess $\mathrm{CBF}$ in multiple brain regions.

A promising alterative to current invasive monitoring techniques is near-infrared spectroscopy (NIRS). Due to the relative transparency of biological tissue to near-infrared (NIR) light, the brain can be interrogated non-invasively by probes placed on the scalp (Jobsis, 1977). Not only is NIRS non-invasive and safe, due to the use of non-ionizing radiation, the major tissue endogenous chromophores - water, oxy- and deoxy-hemoglobin $\left(\mathrm{HbO}_{2}\right.$ and $\left.\mathrm{Hb}\right)$, cytochrome c oxidase, and lipids - have unique absorption properties in this wavelength range. The challenge to quantifying tissue chromophores concentrations with NIRS is the need to account for the strong light scattering, which dominates over light absorption. To meet this challenge, techniques that can take into account the effects of scattering have been developed and NIRS is now widely used to continuously monitor $\mathrm{HbO}_{2}$ and $\mathrm{Hb}$, and derive cerebral blood oxygenation. The most reported NIRS parameter is the ratio of $\mathrm{HbO}_{2}$ to total haemoglobin (i.e., $\mathrm{HbO}_{2}+\mathrm{Hb}$ ), which reflects cerebral blood oxygen saturation and is commonly referred to as the tissue oxygenation index (TOI). The TOI has been proposed for detecting ischemia and 
assessing autoregulation by comparison to MAP (Al-Rawi \& Kirkpatrick, 2006; Brady et al., 2008). The difficulties with using TOI as a surrogate of CBF are that blood oxygenation is influenced by multiple factors (CBF, cerebral metabolism, arterial saturation and hematocrit) and the "normal range" has yet to be defined. Reported TOI values have ranged from 60 to $85 \%$, and this variation is as great as the change attributed to ischemia (Al-Rawi \& Kirkpatrick, 2006; Thavasothy et al., 2002; Yoshitani et al., 2002).

NIRS techniques that can directly measure CBF have been developed. The first method proposed was based on the Fick principle and used a rapid change in arterial oxygen concentration as a blood flow tracer (Edwards et al., 1988). Improved sensitivity was achieved using indocyanine green (ICG) due to its strong light-absorbing properties (Patel et al., 1998). This FDA-approved dye has been in clinical use for over 30 years and has a high safety record; a study involving more than 3000 human subjects, showed that intravenous injection of ICG resulted in significant allergic reaction in only one subject (Hope-Ross et al., 1994). Absolute CBF, rather than a relative measure, was obtained with the ICG approach using a dye densitometer, to measure the arterial blood ICG concentration, a NIRS method capable of quantifying the tissue ICG concentration and a deconvolution method (Brown et al., 2002; Springett et al., 2001). Because of the inherent sensitivity of NIRS to blood oxygenation, $\mathrm{CMRO}_{2}$ can also be measured by combining NIRS measurements of CBF and oxygenation. In addition, $\mathrm{CMRO}_{2}$ has been shown to be a better marker of injury severity in hypoxia-ischemia than CBF alone (Tichauer et al., 2006a). In this chapter we will show that NIRS can be used to measure cerebral blood flow and oxygen metabolism, and to detect general and focal brain injuries.

\section{Theory}

\subsection{Cerebral blood flow model}

The hemodynamics of an organ can be quantified by tracking the passage of a contrast agent through the vascular bed, an approach that has been adapted to imaging modalities including MRI and CT, and to NIRS. With this method, the amount of contrast agent in the organ at a given time $t(Q(t))$ is related to the difference between its arterial $\left(C_{a}(t)\right)$ and venous concentrations $\left(C_{v}(t)\right)$, and to blood flow $(F)$ via the Fick Principle (Meier \& Zierler, 1954):

$$
\frac{d Q(t)}{d t}=F C_{a}(t)-F C_{v}(t)
$$

If $Q(t), C_{a}(t)$ and $C_{v}(t)$ could be measured non-invasively, then the calculation of flood flow would be a simple mathematical operation but that is not the case since $C_{v}(t)$ cannot be measured noninvasively. However, the venous concentration of contrast agent can be expressed in term of $C_{a}(t)$ as (Lee, 2002):

$$
C_{v}(t)=C_{a}(t) * h(t),
$$

where * is the convolution operator and $h(t)$ is the impulse response function of the organ (i.e., the distribution of transit times) and represents the venous concentration of contrast agent if the arterial input was a Dirac-delta function. From Eq. (1) and (2) it can be shown that $Q(t)$ can be expressed as (Lee, 2002):

$$
Q(t)=C_{a}(t) * F \cdot R(t) .
$$


Equation (3) shows that CBF can be determined by measuring $Q(t)$ and $C_{a}(t)$, and applying a deconvolution technique to extract $F \cdot R(t)$. The initial height of the function $F \cdot R(t)$ is $C B F$, as by definition $R(0)=1$, and the area under the curve is the cerebral blood volume (CBV) (Brown et al., 2002). It is clear from Eq. (3) that determining CBF requires the quantification of the tracer concentration in the brain. Fig. 1 shows an example of $Q(t)$ and $C_{a}(t)$ measured on a piglet and the retrieved $F \cdot R(t)$.
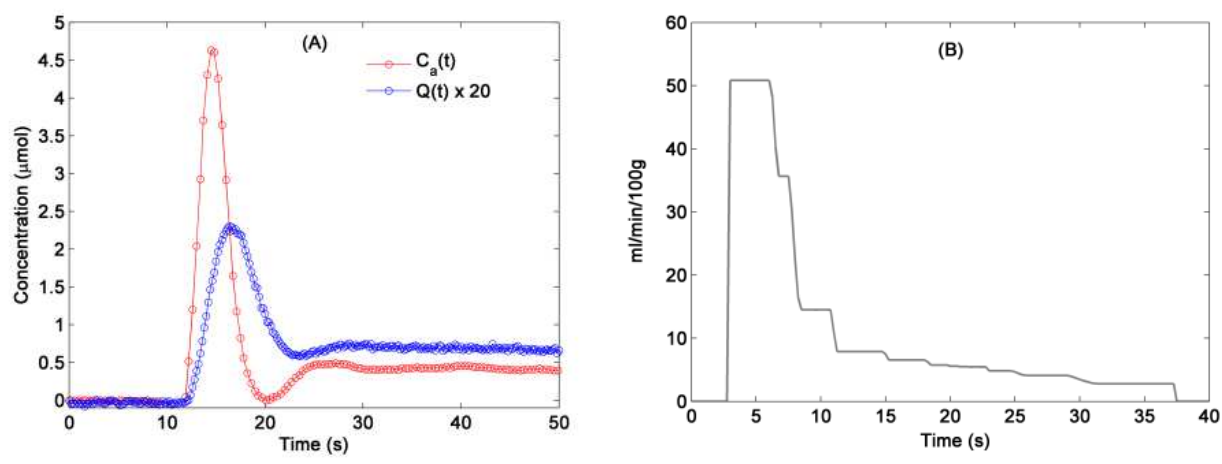

Fig. 1. (A) An example of tissue and arterial ICG concentration curves measured with a NIRS apparatus and a dye densitometer respectively. The curves were measured simultaneously over a period of 50 seconds after injection of an ICG bolus. The peak arterial concentration is approximately 20 times greater than that of tissue. This is because blood volume in tissue is approximately $5 \%$ of the total tissue volume. (B) Cerebral blood flow scaled impulse residue function, $F \cdot R(t)$, retrieved from the deconvolution of the curves in (A). Height of initial plateau yields CBF $(50 \mathrm{ml} / \mathrm{min} / 100 \mathrm{~g})$ and area under the curve is CBV.

\subsection{Measuring the cerebral metabolic rate of oxygen}

The NIRS CBF measurements can be used to determine $\mathrm{CMRO}_{2}$ by applying the Fick Principle (Tichauer et al., 2006b):

$$
\mathrm{CMRO}_{2}=F \cdot\left(\mathrm{AVDO}_{2}\right),
$$

where $\mathrm{AVDO}_{2}$ is the arterial-venous difference of oxygen, or the difference between the oxygen concentration of the arterial system feeding the tissue of interest and the oxygen concentration of the venous system draining the tissue. Assuming that the oxygen content of arterial blood is the same throughout the body (Brown et al., 2003), the arterial $\mathrm{O}_{2}$ concentration can be obtained from hemoximeter analysis of arterial blood samples from a periphery artery or non-invasively from a pulse oximeter. The venous $\mathrm{O}_{2}$ concentration is more difficult to determine non-invasively. However, considering that the $\mathrm{Hb}$ measured in the brain is due solely to $\mathrm{O}_{2}$ dissociation from $\mathrm{HbO}_{2}$, the NIRS measurements of tissue $\mathrm{Hb}$ concentration can be used as an indirect measure of the venous $\mathrm{O}_{2}$ concentration. With this approach, it is necessary to account for the fact that the tissue $\mathrm{Hb}$ concentration is a weighted average of the three blood compartments: arterial, capillary and venous. The relative distribution of arterial, capillary, and venous compartments in the total CBV is generally accepted to be approximately 20\%, 10\%, and 70\% respectively (Phelps et al., 1979). 
Assuming that the capillary concentration of $\mathrm{Hb}$ is the average of arterial and venous concentrations, the venous concentration of $\mathrm{Hb}$ can be expressed as:

$$
[H b]_{V}=\frac{4}{3} \cdot \frac{[H b]_{T}}{C B V \cdot \rho}-\frac{1}{3} \cdot[H b]_{a},
$$

where $[\mathrm{Hb}]_{V},[\mathrm{Hb}]_{T}$, and $[\mathrm{Hb}]_{a}$ are the venous, tissue, and arterial concentrations of $\mathrm{Hb}$, respectively. The tissue $\mathrm{Hb}$ concentration, $[\mathrm{Hb}]_{T}$, is measured by NIRS and $[\mathrm{Hb}]_{a}$ can be measured by either hemoximeter analysis of an arterial blood sample or pulse oximetry. The NIRS measurement of $[\mathrm{Hb}]_{T}$ is normalized by the dilution factor, $\mathrm{CBV} \cdot \rho$, to determine the concentration of $\mathrm{Hb}$ in just the blood compartment of the tissue region of interest. The density of brain tissue, $\rho$, is $1.05 \mathrm{~g} / \mathrm{ml}$ and is used to convert the CBV from volume of blood per mass of tissue to volume of blood per volume of tissue. Finally, with knowledge of the total hemoglobin $\left(\mathrm{tHb}=\mathrm{Hb}+\mathrm{HbO}_{2}\right)$ measured from a blood sample, the venous $\mathrm{O}_{2}$ concentration can be determined as follows (Brown et al., 2003):

$$
\text { Venous } \mathrm{O}_{2} \text { Concentration }=\left([t H b]-[H b]_{v}\right) \cdot 1.39 \mathrm{ml} \mathrm{O}_{2} / \mathrm{gHb} .
$$

\section{Measurement of $Q(t)$ and $\mathrm{Ca}(t)$}

\subsection{Measurement of tissue chromophores concentration}

Fig. 2 shows a picture of the cart housing the broadband continuous-wave NIRS instrument. The main components of the apparatus are the light source, the fiber optic cables (optodes), and the spectrometer. The light source is a power-stabilized halogen light bulb and the spectrometer consists of a holographic grating and a cooled CCD camera. During measurements, the two optodes are placed $3.0 \mathrm{~cm}$ apart on the skull of the subject. One optode is used to guide the light from the source to the head and the other collects light reemitted from the head and transmits it to the holographic grating of the spectrometer, where it is dispersed across the cooled CCD chip (cooled to $70^{\circ} \mathrm{C}$ to reduce electronic dark noise) to generate an attenuation spectrum every $200 \mathrm{~ms}$.

Measured spectra were analyzed on the basis of the principle that when NIR light enters tissue, it is multiply scattered and partially absorbed by endogenous tissue chromophores, such as water, $\mathrm{HbO}_{2}, \mathrm{Hb}$, cytochrome c oxidase, and lipids. Since scattering causes the total pathlength traveled by the NIR light from the emission optode to detection probe to be larger than the physical distance between the two optodes, a simple approach is to take into account the increase in pathlength using the differential pathlength factor (DPF), as first described by Delpy et al. (Delpy et al., 1988). With accurate knowledge of the DPF, a modified version of the Beer-Lambert law can be used to determine absolute changes in the concentrations of the NIR absorbers (Cope, 1991):

$$
\Delta A(\lambda)=\sum_{i} \Delta c_{i} \cdot D P F \cdot L \cdot \varepsilon_{i}(\lambda)
$$

where $\Delta A(\lambda)$ is the change in the attenuation spectra, $\Delta c_{i}$ is the absolute change in concentration of the $i^{\text {th }}$ NIR absorber, $L$ is the physical distance between the emission and detection probes, and $\varepsilon_{i}(\lambda)$ is the extinction coefficient of the $i^{\text {th }}$ NIR absorber as a function of wavelength. In particular, Eq. (7) can be used to quantify tissue ICG concentration, following a bolus injection of the dye, since there is no ICG in the brain prior to the injection. 
Furthermore, the second derivative technique described by Matcher et al. (Matcher et al., 1994) can be applied to the broadband data, in conjunction with the assumption of $85 \%$ water concentration in the brain in infants and $80 \%$ in adults (Matcher \& Cooper, 1994), to obtain the DPF and absolute concentrations of endogenous absorbers - as opposed to absolute changes of concentrations - in real time.

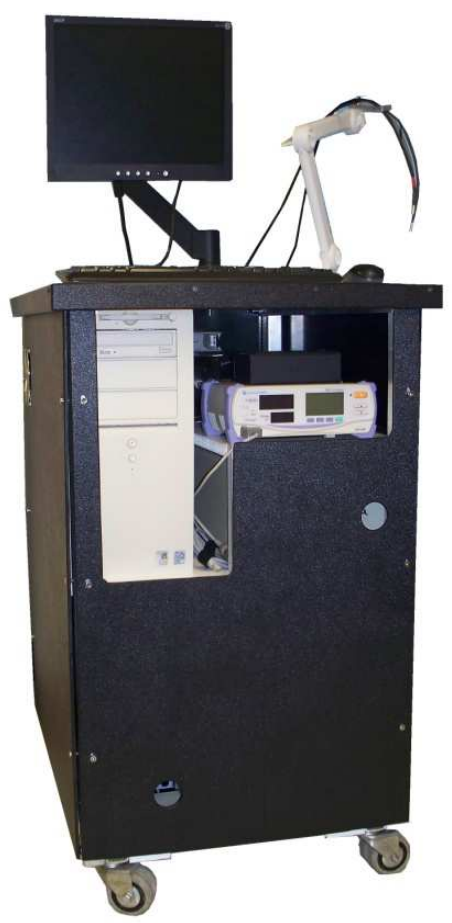

Fig. 2. Picture of the potable NIRS apparatus.

\subsection{Arterial ICG concentration measurement}

Arterial ICG concentration can be measured noninvasively on a peripheral artery (e.g., a foot in the case of a piglet) using a dye densitometer unit (model DDG-2001 A/K, Nihon Kohden, Tokyo, Japan). The probe of the dye densitometer can be held on the skin using a spring-loaded clip, much the same as used for a regular pulse oximeter probe.

\section{Validation experiments}

\subsection{CBF validation}

Cerebral blood flow and blood volume were altered in a newborn piglet model, by changing the partial arterial carbon dioxide tension $\left(\mathrm{PaCO}_{2}\right)$, and concomitantly measured with NIRS and CT perfusion (Brown et al., 2002). Because of the portable nature of the NIRS apparatus, both NIRS and CT measurements were acquired with the piglet in the CT 
scanner. Newborn piglets (less than a week old) were chosen to avoid complications due to extracerebral contamination of the NIRS signal that occurs in older subjects, which is discussed section 6. As shown in Fig. 3, there is a strong linear correlation between CT and NIRS hemodynamic measurements over a wide range. In addition, there is no significant statistical difference between CT and NIRS measurements of CBF and CBV, and the estimated bias are small relative to the respective mean values in each case. The precision of NIRS CBF and CBV measurements - determined using analysis of variance of repeated measurements - were $9.71 \%$ and $13.05 \%$ respectively. These results show that this NIRS technique is capable of accurate and reliable bedside measurement of cerebral hemodynamics in newborn piglets.
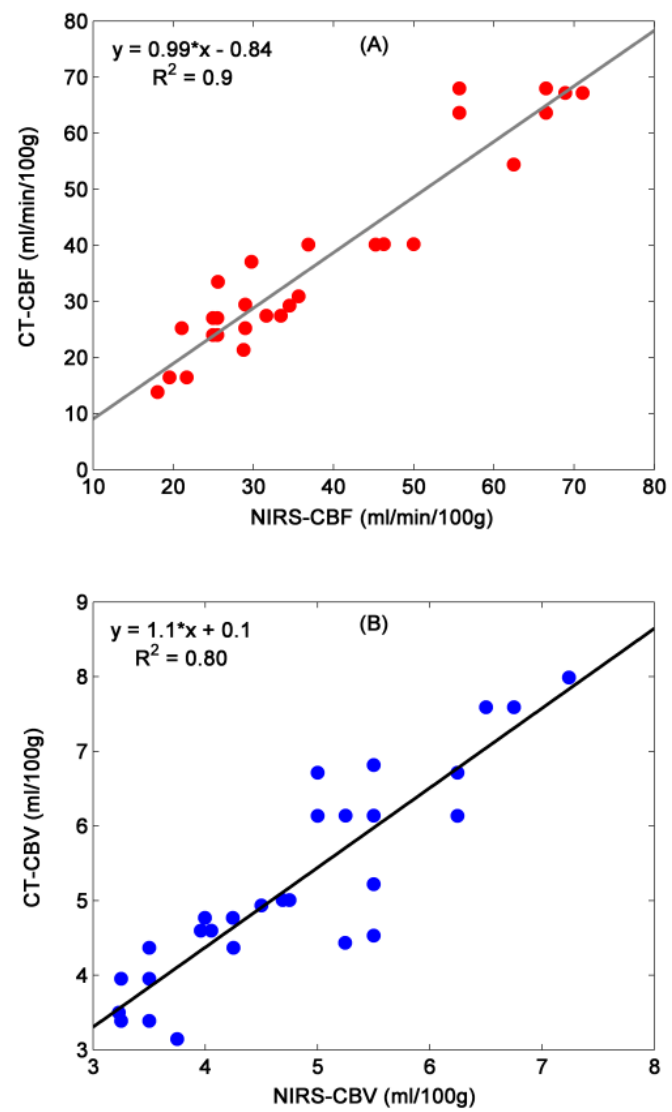

Fig. 3. Comparison of CT and NIRS measurements of cerebral blood flow and blood volume.

There are, however, some challenges facing the clinical application of the technique. Although the piglet head mimics that of a neonate in terms of skull composition and thickness, the two are significantly different in size and dimension. In this validation study an inter-optode distance of $3.0 \mathrm{~cm}$ was used and this yields a maximum depth of light 
penetration of $\sim 1.73 \mathrm{~cm}$ (Brown et al., 2002). This inter-optode separation should be appropriate for neonatal application since it has been shown that in this population, the thickness of the tissue overlying the brain are typically less than $5 \mathrm{~mm}$ and do not significantly interfere with NIR monitoring of the brain for inter-optode distance of at least 3 $\mathrm{cm}$ (Benaron et al., 1995). A potential inconvenience with this technique is that it requires an ICG injection. Although the use of an exogenous blood flow tracer is somewhat less appealing than using one of the endogenous NIR absorbers (for example $\mathrm{HbO}_{2}$ or $\mathrm{Hb}$ ), ICG results in a much higher signal-to-noise ratio.

This study demonstrated the ability of NIRS to accurately measure cerebral hemodynamics at the bedside and showed that this technique can monitor and diagnose ischemic injury in neonates. In ischemic brain injury, $\mathrm{CBF}$ is often low for an extended period of time before symptoms of injury are apparent. The ability to detect diminished CBF at an earlier stage would significantly aid earlier intervention and greatly reduce mortality and morbidity. It has also been suggested that loss of $\mathrm{PaCO}_{2}$ reactivity is associated with poor neurodevelopmental outcome and/or hypoxic-ischemic encephalopothy and that the loss of $\mathrm{PaCO}_{2}$ reactivity is a candidate for predicting early severe brain damage in preterm infants (Blankenberg et al., 1997; Muller et al., 1997). Because the NIRS-CBF technique is capable of providing reliable, non-invasive, repeatable measurements it can be used to detect loss of $\mathrm{PaCO}_{2}$ reactivity, thereby greatly improving diagnosis.

\section{2 $\mathrm{CMRO}_{2}$ validation}

The cerebral metabolic rate of oxygen measured by the NIRS technique were compared to $\mathrm{CMRO}_{2}$ determined from the product of $\mathrm{CBF}$ and the cerebral arterial-venous difference in oxygen $\left(\mathrm{AVDO}_{2}\right)$ measured from blood samples (Tichauer et al., 2006b). The experiments were conducted in newborn piglets subjected to five cerebral metabolic states created by varying the plane of anesthesia. The blood samples were collected from a peripheral artery and the superior sagittal sinus. As such, the two $\mathrm{CMRO}_{2}$ measurements were not collected from exactly the same brain volumes. However, there should be significant overlap between the two sampled volumes since both techniques primarily measure cortical tissue (Scremin et al., 1982). In addition, partial volume errors were avoided by using anesthetics to alter $\mathrm{CMRO}_{2}$ globally (Schultz, 1978). No statistically significant difference was found, within a range of $\sim 1.5$ to $4.0 \mathrm{mlO}_{2} / \mathrm{min} / 100 \mathrm{~g}$, between $\mathrm{CMRO}_{2}$ measurements obtained with the two techniques at any anesthetic level. There was also a strong correlation between concomitant $\mathrm{CMRO}_{2}$ values obtained from the two techniques (Fig. 3 in Tichauer et al., 2006b). Furthermore, repeated measurements obtained while maintaining constant $\mathrm{CMRO}_{2}$ showed that the NIRS technique can measure $\mathrm{CMRO}_{2}$ with a precision of $10.7 \%$. All of this shows that $\mathrm{CMRO}_{2}$ can be determined accurately by combining NIRS measurements of CBF and deoxy-hemoglobin.

It is evident from Eq. 4 that there are two key parameters that must be determined accurately to calculate $\mathrm{CMRO}_{2}: \mathrm{CBF}$ and $\mathrm{AVDO}_{2}$. Due to the difficulty of measuring these parameters, introduced by the high scattering properties of biological tissue, few studies have attempted to measure absolute $\mathrm{CMRO}_{2}$ with NIRS. In this validation, the second derivative technique was applied to broadband data to account for scattering (Matcher et al., 1994) and real-time measurements of the differential pathlength were acquired using the known water concentration in brain (Matcher \& Cooper, 1994). A consequence of the second derivative approach is that the $\mathrm{AVDO}_{2}$ must be calculated solely from the $\mathrm{Hb}$ 
signal as the second derivative of the $\mathrm{HbO}_{2}$ absorption spectrum is relatively featureless (Cope, 1991). With this approach, an independent measure of the arterial oxygenation must be obtained, which can be determined directly from an arterial blood sample or indirectly from the arterial oxygen saturation. It is also necessary to normalize the tissue by $\mathrm{CBV}$, which was obtained from the ICG measurements, and to assume a relative distribution of in the vasculature.

Quantitative measures of $\mathrm{AVDO}_{2}$ were calculated under the assumption that the relative contribution of venous and arterial blood to the total blood volume in the brain is 3:1 (Phelps et al., 1979). Because of its importance, there have been a number of studies that have attempted to measure the relative vascular distribution (Hueber et al., 2001; Kusaka et al., 2002; Watzman et al., 2000; Wiedeman, 1963). These studies compared NIRS tissue oxygenation measurements to oxygenation measurements from arterial and venous blood samples, and found results similar to the 3:1 ratio which was originally derived from cerebrovascular resistance measurements. In addition, it has been shown that the $\mathrm{AVDO}_{2}$ is relatively insensitive to errors in the assumed relative vascular contribution (Tichauer et al., 2010).

\section{Applications}

\subsection{Detection of hypoxia-ischemia}

Recent clinical trials have demonstrated that the incidence of death and disability from hypoxic-ischemic brain injury in newborns can be significantly reduced by initiating treatment strategies - hypothermia for example - after birth and within a $6 \mathrm{~h}$ therapeutic window (Chaudhari \& McGuire, 2008; Eicher et al., 2005a; Eicher et al., 2005b; Gluckman et al., 2005; Shankaran et al., 2005). Due to the brevity of the therapeutic window, early detection of injury and an early determination of those infants who are likely candidates for treatment are crucial (Gunn \& Bennet, 2008). In this regard, traditional early indicators of brain injury - including Apgar scores, umbilical artery acidosis and fetal heart rate monitoring - suffer from poor specificity (Carter et al., 1998; Shankaran, 1998) and more specific indicators of injury, such as magnetic resonance imaging and spectroscopy, are insensitive or difficult to implement within the therapeutic window (Cady, 2001; Martin \& Barkovich, 1995). To this point, the most promising and clinically-feasible monitoring technique for early indicator of hypoxia-ischemia (HI) after birth has been amplitude-integrated electroencephalography (aEEG) due to its ease of use, noninvasiveness and high prognostic value as early as $3 \mathrm{~h}$ after birth (al Naqeeb et al., 1999; Toet et al., 1999). However, recent studies have questioned the sensitivity of aEEG to detect infants with milder injuries that could still benefit from treatment (Sarkar et al., 2008). Another potentially promising early indicator is reduction in $\mathrm{CMRO}_{2}$ since $\mathrm{HI}$ is believed to impair oxidative metabolism.

To test the idea that NIRS-CMRO ${ }_{2}$ measurements can improve early detection of perinatal $\mathrm{HI}$, measurements were acquired in newborn piglets (Tichauer et al., 2009) before and after 1 $\mathrm{h}$ of reperfusion from $\mathrm{HI}-$ the duration of which was varied from piglet to piglet with a range of 3-24 min - under fentanyl/nitrous oxide anesthesia to mimic awake-like levels of cerebral metabolism. $\mathrm{CMRO}_{2}$ was found to be significantly depressed following the insult; mean $\mathrm{CMRO}_{2}$ was $2.61 \pm 0.11 \mathrm{mlO}_{2} \cdot \mathrm{min}^{-1} \cdot 100 \mathrm{~g}-1$ prior to the insult and $1.58 \pm 0.09 \mathrm{mlO}_{2} \cdot \mathrm{min}^{-}$ $1.100 \mathrm{~g}^{-1}$ after $1 \mathrm{~h}$ of reperfusion, respectively. The NIRS-CMRO $\mathrm{C}_{2}$ measurements were combined with aEEG and both measurements displayed statistically significant correlations 
with duration of ischemia ( $p<0.05 ; r=0.71$ and $r=0.89$, respectively); however, only $\mathrm{CMRO}_{2}$ was sensitive to milder injuries (<5 min). These evidences suggest that the NIRS$\mathrm{CMRO}_{2}$ technique has the potential to delineate different insult severities within $1 \mathrm{~h}$ of reperfusion from hypoxia-ischemia in a piglet model of perinatal HI. Since the technique can be applied at the bedside of the sick newborn, these results highlight its potential to improve diagnosis and to monitor treatment of hypoxic-ischemic encephalopathy within the therapeutic window.

\subsection{Focal brain injury}

Although the previous sections highlight the potential of using NIRS for early detection of brain injury in newborns, $\mathrm{CBF}$ and $\mathrm{CMRO}_{2}$ were only measured in a single brain volume as the NIRS instrument had only one detection channel. This limits the clinical applicability of the technique due to selective patterns of damage associated with major causes of neonatal brain injury, such as hypoxia-ischemia and intraventricular hemorrhage, and due to focal injury caused by ischemic stroke. To expand the detection capabilities of the NIRS apparatus to enable the measurements of regional $\mathrm{CBF}$ and $\mathrm{CMRO}_{2}$, a relatively simple multiplexing approach based on electronically controlled mechanical shutters has been proposed (Diop et al., 2009). The entire apparatus was housed in a cart (see Fig. 2) and could be moved to the bedside. The ability of this multi-detector NIRS instrument to detect regional CBF and $\mathrm{CMRO}_{2}$ abnormalities was tested in newborn piglets in which the vasoconstrictor Endothelin-1 (ET-1) was injected into the brain to cause a focal ischemic injury. Endothelin-1 is an amino acid peptide that possesses prolonged and profound vasoconstrictive effects on cerebral blood vessels (Diop et al., 2009). For comparison, regional CBF was concurrently measured by CT perfusion. Due to limited space on the piglet head, only four detection channels were used in that study. A general reduction in CBF was observed across all detection channels with the magnitude decreasing farther from the site of ET-1 injection; a trend that was also observed in the CT perfusion images. An excellent agreement was also observed between CBF in the lesion site, as determined from the CT perfusion images, and CBF measured by the NIRS optode nearest to the lesion site (optode 1 in Fig. 4). The NIRS$\mathrm{CMRO}_{2}$ measurements showed that ET-1 injection did not cause a significant change in cerebral energy metabolism. This was expected as $\mathrm{CMRO}_{2}$ would be maintained, despite the reduction in $\mathrm{CBF}$, by an increase in cerebral oxygen extraction. Although both NIRS and CT measured $\sim 50 \%$ CBF reduction in the lesion region, this decrease was likely not sufficient to exhaust the compensatory effects of increased oxygen extraction. Typically, reductions in $\mathrm{CMRO}_{2}$ are not observed until CBF falls below $25 \mathrm{ml} / 100 \mathrm{~g} / \mathrm{min}$.

A limitation with this multi-channel NIRS apparatus is that it is not immune to partialvolume errors which could result in an overestimation of CBF in focal lesions significantly smaller than the sensitivity volume of a source-detector unit. One approach to improving the spatial resolution would be to combine the multi-channel NIRS instrument with a discrete-wavelength continuous-wave system with multiple emission and detection optodes. Broadband NIRS could be used to determine the DPF and the steady-state $\mathrm{Hb}$ concentration needed to determine $\mathrm{CMRO}_{2}$. A discrete-wavelength imaging system could then be used to rapidly acquire dynamic ICG concentration data. The relative ICG data would be converted into absolute units using the DPF measurements. With such an approach, it may be possible to apply diffuse optical tomographic methods to further improve spatial resolution. 

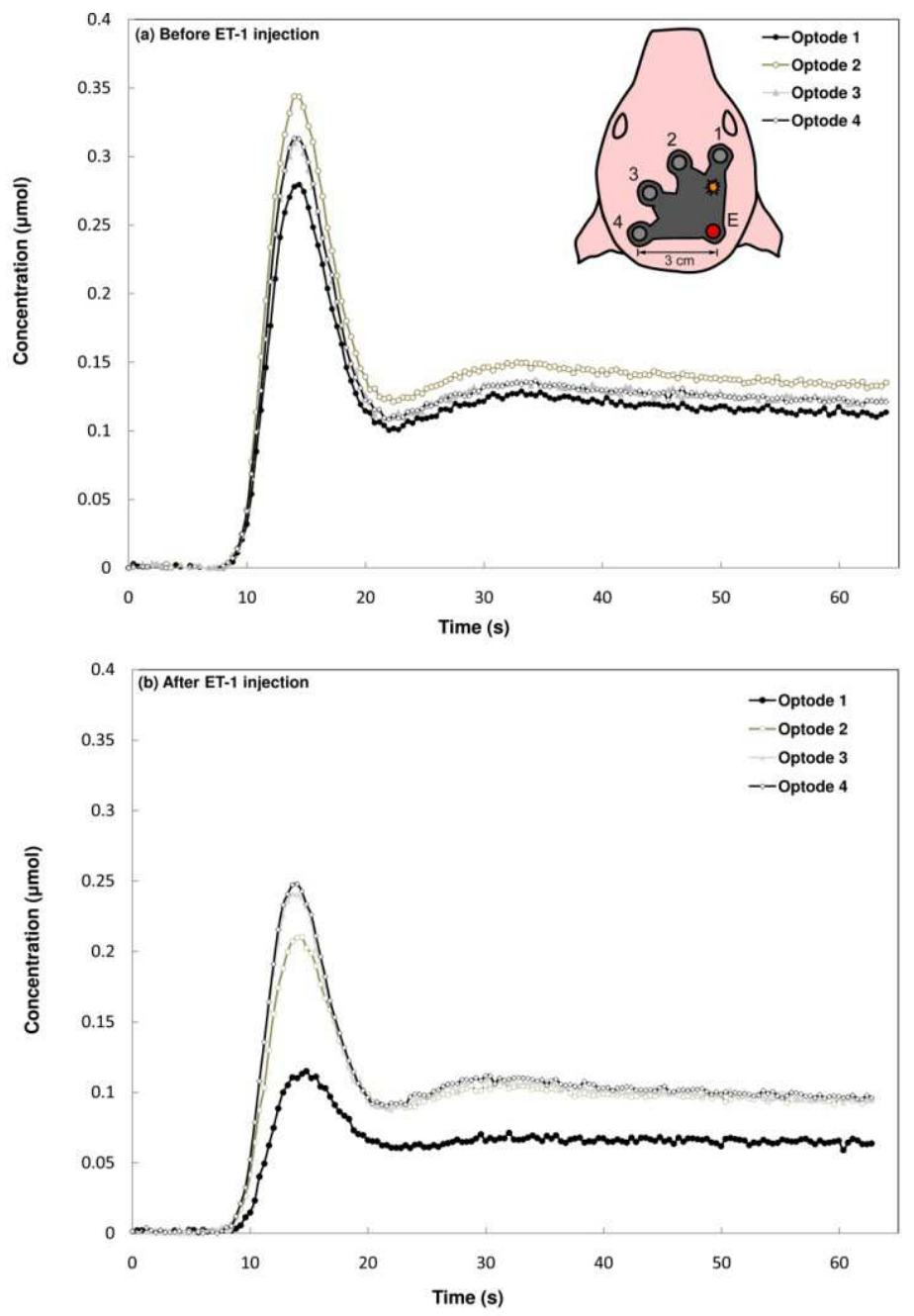

Fig. 4. Brain tissue ICG concentration curves obtained from detection optodes 1-4 before (a) and after (b) ET-1 injection. The reduction in the peak height of the ICG curve for optode 1 after ET-1 injection reflects the reduction in CBF caused by the drug. Shown in the top right hand side of (a) is a cartoon of a piglet head showing the location of the 4 detection optodes (labelled 1-4) relative to the emission optode (labelled E). The emission-detector distance was $3 \mathrm{~cm}$ in all cases. The approximate position of the ET-1 injection site is represented by the orange mark between the emission optode and detection optode 1.

\section{Extra-cerebral signal contamination}

A major obstacle to NIRS clinical applications in adults is the presence of extra-cerebral tissues (scalp, skull and CSF) within the region interrogated by NIRS probes. For CBF 
measurements, the measured ICG tissue concentration curve is comprised of both cerebral and non-cerebral components that are highly correlated. Using tracer kinetic models to recover CBF from a contaminated curve would result in an underestimation of CBF (Elliott et al., 2010; Gora et al., 2002; Owen-Reece et al., 1996). Solutions to overcoming this challenge have been proposed, including more advanced instrumentation as well as analytical approaches, with the main goal of increasing sensitivity to cerebral components. The presence of the extra-cerebral component in the measured signal makes the analytical problem underdetermined when using a single-channel continuous-wave configuration. To differentiate between signal arising from cerebral tissue and extracerebral contamination, more information about the light-tissue interaction is necessary. Several instrumentation approaches have emerged which provide additional information and include multi-distance (also known as spatially resolved), time-resolved and frequency-domain approaches. The additional data provided by these techniques facilitate the removal of extracerebral contamination by further constraining the system of equations which describe the change in light propagation due to the inflow of tracer.

In depth-resolved NIRS, multiple detectors are used to simultaneously measure the optical signal at difference source-detector distances (Hongo et al., 1995; Pucci et al., 2010). This approach is based on the principle that the penetration depth of light increases with sourcedetector distance. Therefore, the distance that light travels in each tissue type depends on both the geometry of the tissue layers as well as the source-detector distance. Measuring the NIR signal at a variety of source-detector distances for the same tissue structure provides a means of algebraically isolating information from the cerebral tissue. The main limitation of this approach is that the mean partial pathlength of light for a given source-detector distance is unknown and must therefore be determined using mathematical modeling, spectral information, anatomical priors, or a combination of these. Recently, a depth-resolved NIRS method that incorporated CT imaging data into a light propagation model has been validated (Elliott et al., 2010). The determination of mean partial pathlengths using this approach allowed the removal of extracerebral contamination, and the recovered CBF values were in good agreement with independent measurements obtained with CT perfusion. Several other multi-distance techniques have been proposed, using time-resolved or frequency-domain methods to provide additional information (Liebert et al., 2004; Steinbrink et al., 2006).

An effective way to isolate the deeper cerebral component of the signal is to collect information about individual photons, mainly the time required to travel from the source fibre, through the tissue, to the detector. This "time-of-flight" is a function of the optical properties of the tissue and the distribution of times-of-flight for a sample of photons can be considered as a unique signature of the tissue geometry and type. Similar to the depthresolved approach, photons with late arrival times are more likely to have propagated into cerebral tissue, but unlike in the case of depth-resolved NIRS, the relationship is not straight-forward. Instead, it is necessary to mathematically model the time-of-flight distribution (Kienle et al., 1998; Wang et al., 1995) to determine the optical properties of each medium. Changes in light attenuation recovered from this modeling can be converted to ICG concentration and deconvolved to yield CBF (Diop et al., 2010).

In a similar way, when a frequency-modulated light signal is introduced into a tissue, the amplitude and phase components of the detected light depend on the tissue geometry and optical properties (Choi et al., 2004). In theory, the same time-of-flight information collected using time-resolved NIRS is contained in frequency-domain measurements. Since most analytical models employed in time-resolved analysis have solutions for the frequency domain as well, the two techniques are theoretically equivalent. 
When using the methods discussed above, a certain amount of prior information is necessary to properly analyze the measured data. These priors include information regarding the geometry and type of tissue being interrogated, the optical properties of the tissues, and the placement and efficiency of the optical probes. Because the determination of these priors can often be challenging in a clinical environment, it is common to make a limited number of assumptions and simplifications. However, the number and quality of priors will usually affect the accuracy of the CBF measurement, making it necessary to carefully consider this trade-off.

Perhaps the most important prior from a clinical perspective is anatomical information pertaining to the thickness and shape of the extracerebral layers, and must be incorporated into light propagation models. In the absence of this information, the head is treated either as a homogenous medium or as a simple two-layered structure with a top layer thickness based on the population average. Measurements of CBF determined using either of these two assumptions have been shown to be inaccurate under most clinical situations (Gora et al., 2002; Schytz et al., 2009). The accuracy of CBF measurements can be improved when the total thickness of the extra-cerebral layer, or preferably, the individual thicknesses of the scalp, skull and CSF layers are known (Elliott et al., 2010). Recent studies have also suggested that incorporating an imaging dataset from CT or MRI may further increase the accuracy of the measurements (Dehaes et al., 2011), but this has not yet been demonstrated experimentally.

An alternative approach to the quantitative methods discussed above is to use semiquantitative comparisons to assess the relative change in blood flow as a function of time, or the relative difference in blood flow between different areas on the head (Liebert et al., 2005). While these techniques cannot quantify $\mathrm{CBF}$, they may be effective in specific clinical applications even if no priors are available. Recently, Steinkeller et al. demonstrated the use of a semi-quantitative time-resolved NIRS technique to monitor cerebral perfusion in acute ischemic stroke patients (Steinkellner et al., 2010). In this study, NIRS measurements were acquired over both hemispheres following the injection of tracer, and the time-to-peak, or time between first appearance of tracer and the peak concentration of tracer, was determined. In all patients, a larger time-to-peak was observed in the affected hemisphere, when compared to the normal hemisphere.

\section{Conclusion}

Near-infrared spectroscopy is already an accepted and widely used monitoring tool for the clinical management of patients since the ubiquitous pulse oximeter is in fact a NIRS instrument. Although NIRS instruments are in general relatively simple, analyzing the measured signal is not always straightforward. For this reason, interpreting NIRS data remains one of the major obstacles preventing its wide spread and routine clinical use. To overcome this challenge, better analytical tools need to be developed as well as stronger collaboration between researchers and clinicians. Another major problem with NIRS is the lack of widely accepted standards. Efforts are being made to solve this issue with multiple research groups working together to develop calibrated tissue mimicking phantoms.

\section{Acknowledgment}

The authors would like to thank the financial support of the Canadian Institutes of Health Research (CIHR), the Natural Sciences and Engineering Research Council of Canada (NSERC), the Canada Foundation for Innovation, Heart and Stroke Foundation Ontario and the Ontario Neurotrauma Foundation. 


\section{References}

Al-Rawi, P. G. \& Kirkpatrick, P. J. (2006): Tissue oxygen index: thresholds for cerebral ischemia using near-infrared spectroscopy. Stroke,Vol.37.11: 2720

al Naqeeb, N., Edwards, A. D., Cowan, F. M. \& Azzopardi, D. (1999): Assessment of neonatal encephalopathy by amplitude-integrated electroencephalography. Pediatrics,Vol.103.6 Pt 1: 1263

Asgeirsson, B., Grande, P. O. \& Nordstrom, C. H. (1994): A new therapy of post-trauma brain oedema based on haemodynamic principles for brain volume regulation. Intensive Care Med,Vol.20.4: 260

Benaron, D. A., Kurth, C. D., Steven, J. M., Delivoria-Papadopoulos, M. \& Chance, B. (1995): Transcranial optical path length in infants by near-infrared phase-shift spectroscopy. J Clin Monit,Vol.11.2: 109

Blankenberg, F. G., Loh, N. N., Norbash, A. M., Craychee, J. A., Spielman, D. M., Person, B. L., Berg, C. A. \& Enzmann, D. R. (1997): Impaired cerebrovascular autoregulation after hypoxic-ischemic injury in extremely low-birth-weight neonates: detection with power and pulsed wave Doppler US. Radiology,Vol.205.2: 563

Bolognese, P., Miller, J. I., Heger, I. M. \& Milhorat, T. H. (1993): Laser-Doppler flowmetry in neurosurgery. J Neurosurg Anesthesiol,Vol.5.3: 151

Brady, K. M., Lee, J. K., Kibler, K. K., Easley, R. B., Koehler, R. C. \& Shaffner, D. H. (2008): Continuous measurement of autoregulation by spontaneous fluctuations in cerebral perfusion pressure: comparison of 3 methods. Stroke,Vol.39.9: 2531

Bratton, S. L., Chestnut, R. M., Ghajar, J., McConnell Hammond, F. F., Harris, O. A., Hartl, R., Manley, G. T., Nemecek, A., Newell, D. W., Rosenthal, G., Schouten, J., Shutter, L., Timmons, S. D., Ullman, J. S., Videtta, W., Wilberger, J. E. \& Wright, D. W. (2007a): Guidelines for the management of severe traumatic brain injury. IX. Cerebral perfusion thresholds. J Neurotrauma,Vol.24 Suppl 1559

Bratton, S. L., Chestnut, R. M., Ghajar, J., McConnell Hammond, F. F., Harris, O. A., Hartl, R., Manley, G. T., Nemecek, A., Newell, D. W., Rosenthal, G., Schouten, J., Shutter, L., Timmons, S. D., Ullman, J. S., Videtta, W., Wilberger, J. E. \& Wright, D. W. (2007b): Guidelines for the management of severe traumatic brain injury. VIII. Intracranial pressure thresholds. J Neurotrauma,Vol.24 Suppl $1 S 55$

Brown, D. W., Hadway, J. \& Lee, T. Y. (2003): Near-infrared spectroscopy measurement of oxygen extraction fraction and cerebral metabolic rate of oxygen in newborn piglets. Pediatr Res, Vol.54.6: 861

Brown, D. W., Picot, P. A., Naeini, J. G., Springett, R., Delpy, D. T. \& Lee, T. Y. (2002): Quantitative near infrared spectroscopy measurement of cerebral hemodynamics in newborn piglets. Pediatr Res,Vol.51.5: 564

Cady, E. B. (2001): Magnetic resonance spectroscopy in neonatal hypoxic-ischaemic insults. Childs Nerv Syst,Vol.17.3: 145

Carter, B. S., McNabb, F. \& Merenstein, G. B. (1998): Prospective validation of a scoring system for predicting neonatal morbidity after acute perinatal asphyxia. J Pediatr, Vol.132.4: 619

Chaudhari, T. \& McGuire, W. (2008): Allopurinol for preventing mortality and morbidity in newborn infants with suspected hypoxic-ischaemic encephalopathy. Cochrane Database Syst Rev.2: CD006817

Choi, J., Wolf, M., Toronov, V., Wolf, U., Polzonetti, C., Hueber, D., Safonova, L. P., Gupta, R., Michalos, A., Mantulin, W. \& Gratton, E. (2004): Noninvasive determination of the 
optical properties of adult brain: near-infrared spectroscopy approach. J Biomed Opt,Vol.9.1: 221

Coles, J. P., Steiner, L. A., Johnston, A. J., Fryer, T. D., Coleman, M. R., Smieleweski, P., Chatfield, D. A., Aigbirhio, F., Williams, G. B., Boniface, S., Rice, K., Clark, J. C., Pickard, J. D. \& Menon, D. K. (2004): Does induced hypertension reduce cerebral ischaemia within the traumatized human brain? Brain,Vol.127.Pt 11: 2479

Cope, M. (1991): The application of near infrared spectroscopy to non invasive monitoring of cerebral oxygenation in the newborn infant. Ph. D., University College London, London, U.K.

Cremer, O. L. (2008): Does ICP monitoring make a difference in neurocritical care? Eur J Anaesthesiol Suppl,Vol.4287

Dehaes, M., Grant, P. E., Sliva, D. D., Roche-Labarbe, N., Pienaar, R., Boas, D. A., Franceschini, M. A. \& Selb, J. (2011): Assessment of the frequency-domain multi-distance method to evaluate the brain optical properties: Monte Carlo simulations from neonate to adult. Biomed Opt Express,Vol.2.3: 552

Delpy, D. T., Cope, M., van der Zee, P., Arridge, S., Wray, S. \& Wyatt, J. (1988): Estimation of optical pathlength through tissue from direct time of flight measurement. Phys Med Biol,Vol.33.12: 1433

DeWitt, D. S. \& Prough, D. S. (2003): Traumatic cerebral vascular injury: the effects of concussive brain injury on the cerebral vasculature. J Neurotrauma,Vol.20.9: 795

Diop, M., Elliott, J. T., Tichauer, K. M., Lee, T. Y. \& St Lawrence, K. (2009): A broadband continuous-wave multichannel near-infrared system for measuring regional cerebral blood flow and oxygen consumption in newborn piglets. Rev Sci Instrum,Vol.80.5: 054302

Diop, M., Tichauer, K. M., Elliott, J. T., Migueis, M., Lee, T. Y. \& St Lawrence, K. (2010): Comparison of time-resolved and continuous-wave near-infrared techniques for measuring cerebral blood flow in piglets. J Biomed Opt,Vol.15.5: 057004

Edwards, A. D., Wyatt, J. S., Richardson, C., Delpy, D. T., Cope, M. \& Reynolds, E. O. (1988): Cotside measurement of cerebral blood flow in ill newborn infants by near infrared spectroscopy. Lancet, Vol.2.8614: 770

Eicher, D. J., Wagner, C. L., Katikaneni, L. P., Hulsey, T. C., Bass, W. T., Kaufman, D. A., Horgan, M. J., Languani, S., Bhatia, J. J., Givelichian, L. M., Sankaran, K. \& Yager, J. Y. (2005a): Moderate hypothermia in neonatal encephalopathy: efficacy outcomes. Pediatr Neurol,Vol.32.1: 11

Eicher, D. J., Wagner, C. L., Katikaneni, L. P., Hulsey, T. C., Bass, W. T., Kaufman, D. A., Horgan, M. J., Languani, S., Bhatia, J. J., Givelichian, L. M., Sankaran, K. \& Yager, J. Y. (2005b): Moderate hypothermia in neonatal encephalopathy: safety outcomes. Pediatr Neurol,Vol.32.1: 18

Elliott, J. T., Diop, M., Tichauer, K. M., Lee, T. Y. \& St Lawrence, K. (2010): Quantitative measurement of cerebral blood flow in a juvenile porcine model by depth-resolved near-infrared spectroscopy. J Biomed Opt,Vol.15.3: 037014

Gallagher, C. N., Hutchinson, P. J. \& Pickard, J. D. (2007): Neuroimaging in trauma. Curr Opin Neurol,Vol.20.4: 403

Gluckman, P. D., Wyatt, J. S., Azzopardi, D., Ballard, R., Edwards, A. D., Ferriero, D. M., Polin, R. A., Robertson, C. M., Thoresen, M., Whitelaw, A. \& Gunn, A. J. (2005): Selective head cooling with mild systemic hypothermia after neonatal encephalopathy: multicentre randomised trial. Lancet,Vol.365.9460: 663

Gora, F., Shinde, S., Elwell, C. E., Goldstone, J. C., Cope, M., Delpy, D. T. \& Smith, M. (2002): Noninvasive measurement of cerebral blood flow in adults using near-infrared spectroscopy and indocyanine green: a pilot study. J Neurosurg Anesthesiol,Vol.14.3: 218 
Gowda, N. K., Agrawal, D., Bal, C., Chandrashekar, N., Tripati, M., Bandopadhyaya, G. P., Malhotra, A. \& Mahapatra, A. K. (2006): Technetium Tc-99m ethyl cysteinate dimer brain single-photon emission $\mathrm{CT}$ in mild traumatic brain injury: a prospective study. AJNR Am J Neuroradiol,Vol.27.2: 447

Gunn, A. J. \& Bennet, L. (2008): Timing of injury in the fetus and neonate. Curr Opin Obstet Gynecol,Vol.20.2: 175

Helmy, A., Vizcaychipi, M. \& Gupta, A. K. (2007): Traumatic brain injury: intensive care management. Br J Anaesth,Vol.99.1: 32

Hongo, K., Kobayashi, S., Okudera, H., Hokama, M. \& Nakagawa, F. (1995): Noninvasive cerebral optical spectroscopy: depth-resolved measurements of cerebral haemodynamics using indocyanine green. Neurol Res,Vol.17.2: 89

Hope-Ross, M., Yannuzzi, L. A., Gragoudas, E. S., Guyer, D. R., Slakter, J. S., Sorenson, J. A., Krupsky, S., Orlock, D. A. \& Puliafito, C. A. (1994): Adverse reactions due to indocyanine green. Ophthalmology,Vol.101.3: 529

Hueber, D. M., Franceschini, M. A., Ma, H. Y., Zhang, Q., Ballesteros, J. R., Fantini, S., Wallace, D., Ntziachristos, V. \& Chance, B. (2001): Non-invasive and quantitative near-infrared haemoglobin spectrometry in the piglet brain during hypoxic stress, using a frequency-domain multidistance instrument. Phys Med Biol,Vol.46.1: 41

Jobsis, F. F. (1977): Noninvasive, infrared monitoring of cerebral and myocardial oxygen sufficiency and circulatory parameters. Science,Vol.198.4323: 1264

Kienle, A., Patterson, M. S., Dognitz, N., Bays, R., Wagninures, G. \& van den Bergh, H. (1998): Noninvasive Determination of the Optical Properties of Two-Layered Turbid Media. Appl Opt,Vol.37.4: 779

Kirkpatrick, P. J., Smielewski, P., Czosnyka, M. \& Pickard, J. D. (1994): Continuous monitoring of cortical perfusion by laser Doppler flowmetry in ventilated patients with head injury. J Neurol Neurosurg Psychiatry,Vol.57.11: 1382

Kusaka, T., Isobe, K., Nagano, K., Okubo, K., Yasuda, S., Kondo, M., Itoh, S., Hirao, K. \& Onishi, S. (2002): Quantification of cerebral oxygenation by full-spectrum nearinfrared spectroscopy using a two-point method. Comp Biochem Physiol A Mol Integr Physiol,Vol.132.1: 121

Lee, T.-Y. (2002): Functional CT: physiological models. Trends in Biotechnology,Vol.20.8: S3

Liebert, A., Wabnitz, H., Steinbrink, J., Moller, M., Macdonald, R., Rinneberg, H., Villringer, A. \& Obrig, H. (2005): Bed-side assessment of cerebral perfusion in stroke patients based on optical monitoring of a dye bolus by time-resolved diffuse reflectance. Neuroimage,Vol.24.2: 426

Liebert, A., Wabnitz, H., Steinbrink, J., Obrig, H., Moller, M., Macdonald, R., Villringer, A. \& Rinneberg, H. (2004): Time-resolved multidistance near-infrared spectroscopy of the adult head: intracerebral and extracerebral absorption changes from moments of distribution of times of flight of photons. Appl Opt,Vol.43.15: 3037

Martin, E. \& Barkovich, A. J. (1995): Magnetic resonance imaging in perinatal asphyxia. Arch Dis Child Fetal Neonatal Ed,Vol.72.1: F62

Matcher, S. J. \& Cooper, C. E. (1994): Absolute quantification of deoxyhaemoglobin concentration in tissue near infrared spectroscopy. Phys Med Biol,Vol.39.8: 1295

Matcher, S. J., Cope, M. \& Delpy, D. T. (1994): Use of the water absorption spectrum to quantify tissue chromophore concentration changes in near-infrared spectroscopy. Phys Med Biol,Vol.39.1: 177

Meier, P. \& Zierler, K. L. (1954): On the theory of the indicator-dilution method for measurement of blood flow and volume. J Appl Physiol,Vol.6.12: 731 
Muller, A. M., Morales, C., Briner, J., Baenziger, O., Duc, G. \& Bucher, H. U. (1997): Loss of CO2 reactivity of cerebral blood flow is associated with severe brain damage in mechanically ventilated very low birth weight infants. Eur J Paediatr Neurol,Vol.1.5-6: 157

Owen-Reece, H., Elwell, C. E., Harkness, W., Goldstone, J., Delpy, D. T., Wyatt, J. S. \& Smith, M. (1996): Use of near infrared spectroscopy to estimate cerebral blood flow in conscious and anaesthetized adult subjects. Br J Anaesth,Vol.76.1: 43

Patel, J., Marks, K., Roberts, I., Azzopardi, D. \& Edwards, A. D. (1998): Measurement of cerebral blood flow in newborn infants using near infrared spectroscopy with indocyanine green. Pediatr Res,Vol.43.1: 34

Phelps, M. E., Huang, S. C., Hoffman, E. J. \& Kuhl, D. E. (1979): Validation of tomographic measurement of cerebral blood volume with C-11-labeled carboxyhemoglobin. J Nucl Med,Vol.20.4: 328

Pucci, O., Toronov, V. \& St Lawrence, K. Measurement of the optical properties of a twolayer model of the human head using broadband near-infrared spectroscopy. Appl Opt,Vol.49.32: 6324

Robertson, C. S., Valadka, A. B., Hannay, H. J., Contant, C. F., Gopinath, S. P., Cormio, M., Uzura, M. \& Grossman, R. G. (1999): Prevention of secondary ischemic insults after severe head injury. Crit Care Med,Vol.27.10: 2086

Sarkar, S., Barks, J. D. \& Donn, S. M. (2008): Should amplitude-integrated electroencephalography be used to identify infants suitable for hypothermic neuroprotection? J Perinatol,Vol.28.2: 117

Schultz, J. E. (1978): Brain Energy Metabolism. Von B. K. Siesjö, John Wiley and Sons, Chichester, New York, Brisbane Toronto, 1978, 607 S., DM 78,65. Pharmazie in unserer Zeit,Vol.7.6: 192

Schytz, H. W., Wienecke, T., Jensen, L. T., Selb, J., Boas, D. A. \& Ashina, M. (2009): Changes in cerebral blood flow after acetazolamide: an experimental study comparing nearinfrared spectroscopy and SPECT. Eur J Neurol,Vol.16.4: 461

Scremin, O. U., Sonnenschein, R. R. \& Rubinstein, E. H. (1982): Cerebrovascular anatomy and blood flow measurements in the rabbit. J Cereb Blood Flow Metab,Vol.2.1: 55

Shankaran, S. (1998): Identification of term infants at risk for neonatal morbidity. J Pediatr, Vol.132.4: 571

Shankaran, S., Laptook, A. R., Ehrenkranz, R. A., Tyson, J. E., McDonald, S. A., Donovan, E. F., Fanaroff, A. A., Poole, W. K., Wright, L. L., Higgins, R. D., Finer, N. N., Carlo, W. A., Duara, S., Oh, W., Cotten, C. M., Stevenson, D. K., Stoll, B. J., Lemons, J. A., Guillet, R. \& Jobe, A. H. (2005): Whole-body hypothermia for neonates with hypoxic-ischemic encephalopathy. N Engl J Med,Vol.353.15: 1574

Sioutos, P. J., Orozco, J. A., Carter, L. P., Weinand, M. E., Hamilton, A. J. \& Williams, F. C. (1995): Continuous regional cerebral cortical blood flow monitoring in head-injured patients. Neurosurgery, Vol.36.5: 943

Soustiel, J. F., Mahamid, E., Goldsher, D. \& Zaaroor, M. (2008): Perfusion-CT for early assessment of traumatic cerebral contusions. Neuroradiology,Vol.50.2: 189

Springett, R., Sakata, Y. \& Delpy, D. T. (2001): Precise measurement of cerebral blood flow in newborn piglets from the bolus passage of indocyanine green. Phys Med Biol,Vol.46.8: 2209

Steinbrink, J., Fischer, T., Kuppe, H., Hetzer, R., Uludag, K., Obrig, H. \& Kuebler, W. M. (2006): Relevance of depth resolution for cerebral blood flow monitoring by nearinfrared spectroscopic bolus tracking during cardiopulmonary bypass. J Thorac Cardiovasc Surg,Vol.132.5: 1172 
Steinkellner, O., Gruber, C., Wabnitz, H., Jelzow, A., Steinbrink, J., Fiebach, J. B., Macdonald, R. \& Obrig, H. (2010): Optical bedside monitoring of cerebral perfusion: technological and methodological advances applied in a study on acute ischemic stroke. J Biomed Opt,Vol.15.6: 061708

Thavasothy, M., Broadhead, M., Elwell, C., Peters, M. \& Smith, M. (2002): A comparison of cerebral oxygenation as measured by the NIRO 300 and the INVOS 5100 NearInfrared Spectrophotometers. Anaesthesia,Vol.57.10: 999

Tichauer, K. M., Brown, D. W., Hadway, J., Lee, T. Y. \& St Lawrence, K. (2006a): Nearinfrared spectroscopy measurements of cerebral blood flow and oxygen consumption following hypoxia-ischemia in newborn piglets. $J$ Appl Physiol,Vol.100.3: 850

Tichauer, K. M., Elliott, J. T., Hadway, J. A., Lee, D. S., Lee, T. Y. \& St Lawrence, K. (2010): Using near-infrared spectroscopy to measure cerebral metabolic rate of oxygen under multiple levels of arterial oxygenation in piglets. J Appl Physiol,Vol.109.3: 878

Tichauer, K. M., Elliott, J. T., Hadway, J. A., Lee, T. Y. \& St Lawrence, K. (2009): Cerebral metabolic rate of oxygen and amplitude-integrated electroencephalography during early reperfusion after hypoxia-ischemia in piglets. J Appl Physiol,Vol.106.5: 1506

Tichauer, K. M., Hadway, J. A., Lee, T. Y. \& St Lawrence, K. (2006b): Measurement of cerebral oxidative metabolism with near-infrared spectroscopy: a validation study. J Cereb Blood Flow Metab,Vol.26.5: 722

Toet, M. C., Hellstrom-Westas, L., Groenendaal, F., Eken, P. \& de Vries, L. S. (1999): Amplitude integrated EEG 3 and 6 hours after birth in full term neonates with hypoxic-ischaemic encephalopathy. Arch Dis Child Fetal Neonatal Ed,Vol.81.1: F19

Vajkoczy, P., Horn, P., Bauhuf, C., Munch, E., Hubner, U., Ing, D., Thome, C., PoecklerSchoeninger, C., Roth, H. \& Schmiedek, P. (2001): Effect of intra-arterial papaverine on regional cerebral blood flow in hemodynamically relevant cerebral vasospasm. Stroke, Vol.32.2: 498

Valdueza, J. M., Balzer, J. O., Villringer, A., Vogl, T. J., Kutter, R. \& Einhaupl, K. M. (1997): Changes in blood flow velocity and diameter of the middle cerebral artery during hyperventilation: assessment with MR and transcranial Doppler sonography. AJNR Am J Neuroradiol,Vol.18.10: 1929

Wang, L., Jacques, S. L. \& Zheng, L. (1995): MCML--Monte Carlo modeling of light transport in multi-layered tissues. Comput Methods Programs Biomed,Vol.47.2: 131

Watzman, H. M., Kurth, C. D., Montenegro, L. M., Rome, J., Steven, J. M. \& Nicolson, S. C. (2000): Arterial and venous contributions to near-infrared cerebral oximetry. Anesthesiology,Vol.93.4: 947

Wiedeman, M. P. (1963): Dimensions of blood vessels from distributing artery to collecting vein. Circ Res,Vol.12375

Wintermark, M., Sesay, M., Barbier, E., Borbely, K., Dillon, W. P., Eastwood, J. D., Glenn, T. C., Grandin, C. B., Pedraza, S., Soustiel, J. F., Nariai, T., Zaharchuk, G., Caille, J. M., Dousset, V. \& Yonas, H. (2005): Comparative overview of brain perfusion imaging techniques. Stroke,Vol.36.9: e83

Wright, W. L. (2007): Multimodal monitoring in the ICU: when could it be useful? J Neurol Sci,Vol.261.1-2: 10

Yoshitani, K., Kawaguchi, M., Tatsumi, K., Kitaguchi, K. \& Furuya, H. (2002): A comparison of the INVOS 4100 and the NIRO 300 near-infrared spectrophotometers. Anesth Analg,Vol.94.3: 586 


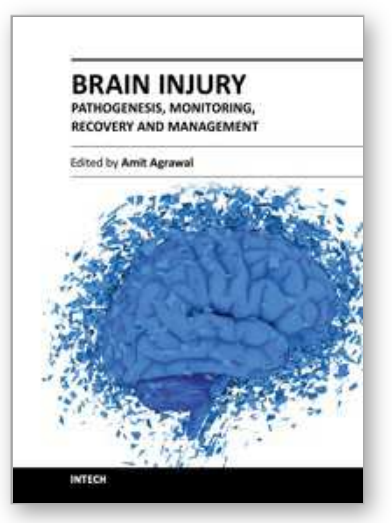

\author{
Brain Injury - Pathogenesis, Monitoring, Recovery and \\ Management \\ Edited by Prof. Amit Agrawal
}

ISBN 978-953-51-0265-6

Hard cover, 522 pages

Publisher InTech

Published online 23, March, 2012

Published in print edition March, 2012

The present two volume book "Brain Injury" is distinctive in its presentation and includes a wealth of updated information on many aspects in the field of brain injury. The Book is devoted to the pathogenesis of brain injury, concepts in cerebral blood flow and metabolism, investigative approaches and monitoring of brain injured, different protective mechanisms and recovery and management approach to these individuals, functional and endocrine aspects of brain injuries, approaches to rehabilitation of brain injured and preventive aspects of traumatic brain injuries. The collective contribution from experts in brain injury research area would be successfully conveyed to the readers and readers will find this book to be a valuable guide to further develop their understanding about brain injury.

\title{
How to reference
}

In order to correctly reference this scholarly work, feel free to copy and paste the following:

Mamadou Diop, Jonathan T. Elliott, Ting-Yim Lee and Keith St. Lawrence (2012). Towards Non-Invasive Bedside Monitoring of Cerebral Blood Flow and Oxygen Metabolism in Brain-Injured Patients with NearInfrared Spectroscopy, Brain Injury - Pathogenesis, Monitoring, Recovery and Management, Prof. Amit Agrawal (Ed.), ISBN: 978-953-51-0265-6, InTech, Available from: http://www.intechopen.com/books/braininjury-pathogenesis-monitoring-recovery-and-management/towards-non-invasive-bedside-monitoring-ofcerebral-blood-flow-and-oxygen-metabolism-in-brain-injure

\section{INTECH}

open science | open minds

\section{InTech Europe}

University Campus STeP Ri

Slavka Krautzeka 83/A

51000 Rijeka, Croatia

Phone: +385 (51) 770447

Fax: $+385(51) 686166$

www.intechopen.com

\section{InTech China}

Unit 405, Office Block, Hotel Equatorial Shanghai

No.65, Yan An Road (West), Shanghai, 200040, China

中国上海市延安西路65号上海国际贵都大饭店办公楼 405 单元

Phone: +86-21-62489820

Fax: $+86-21-62489821$ 
(C) 2012 The Author(s). Licensee IntechOpen. This is an open access article distributed under the terms of the Creative Commons Attribution 3.0 License, which permits unrestricted use, distribution, and reproduction in any medium, provided the original work is properly cited. 